\title{
The Working of the Atomic Force Microscope for Chemical Mapping
}

\author{
Darapond Triampo ${ }^{* 1}$ and Wannapong Triampo ${ }^{2}$
}

\author{
${ }^{I}$ Department of Chemistry and Center for Innovation in Chemistry, Faculty of Science, Mahidol University, Rama 6 Rd., \\ Rajchataywee, Bangkok 10400, Thailand \\ ${ }^{2}$ Department of Physics and Center of Excellence for Vectors and Vector-Borne Diseases, Faculty of Science, Mahidol \\ University, Rama 6 Rd., Rajchataywee, Bangkok 10400, Thailand
}

\begin{abstract}
Since the invention of the scanning tunneling microscope (STM) in 1981 and the atomic force microscope (AFM) in 1986, over 5,000 publications have cited the article "Atomic Force Microscope" by G. Binnig, C.F. Quate, and C. Gerber (published in Physical Review Letters, 1986). This article presents a short review on the operating principle and possible applications of AFM with special attention devoted to chemical mapping. The article would be useful for beginners in AFM technique.
\end{abstract}

In 1959, Nobel Laureate Richard Feynman (Fig. 1), from http://nobelprize.org/nobel_prizes/physics/laureates/1965/ind ex.html) gave a lecture at a meeting of the American Physical Society where he talked about future opportunities for manipulating and controlling things on the very small scale - the nanoscale. It was the first time that the field of nanotechnology was posed to the world. In his talk, Feynman mentioned how in the year 2000 we might look back and wonder why it was not until the year 1960 that we began seriously to move into the field of nanotechnology. Ironically, nanotechnology eventually took off in the year 2000 because back in 1960, we simply did not have the tools to manipulate, control, or characterize things on the nanoscale. The invention of the scanning tunneling microscope (STM) and atomic force microscope (AFM) were major breakthroughs that opened the door to nanotechnology $[1,2]$.

Since the invention of the STM in 1981 and the AFM in 1986, over 5,000 publications have cited the article "Atomic Force Microscope" by G. Binnig, C.F. Quate, and C. Gerber (published in Physical Review Letters, 1986) [1,3]. And because of the continued research and development of these microscopes, together with their versatility, different surface types can be studied today by over 20 modified force microscopes, such as the magnetic force microscope (MFM), force modulation microscope (FMM), Kelvin probe force microscope (KPFM), electrostatic force microscope (EFM), and others. In this article, we aim to describe how chemical force microscopy (CFM) works and its application in providing chemical information of scanned surfaces.

\section{INVENTION OF THE TOOLS}

Gerd Binnig and Heinrich Rohrer developed a prototype of the STM in 1981 while working at the IBM Zurich Research Laboratory in Switzerland. They were later

*Address correspondence to this author at the Department of Chemistry, Faculty of Science, Mahidol University, Rama 6 Rd., Rajchataywee, Bangkok 10400, Thailand; Tel: +662-441-9817, Ext. 1126; Fax: +662-8892337; E-mail: scdar@mahidol.ac.th

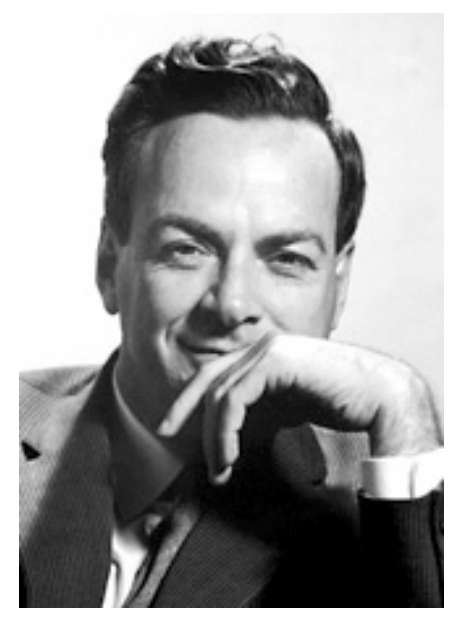

Fig. (1). Nobel Laureate Richard P. Feymann, (picture from http://nobelprize.org/nobel_prizes/physics/laureates/1965/index.htm 1). His prize was shared with 3 other scientists for "their fundamental work in quantum electrodynamics, with deepploughing consequences for the physics of elementary particles".

rewarded with the Nobel Prize in Physics in 1986 for the invention. (The prize was shared that year with Ernst Ruska for his design of the electron microscope. Fig. (2), from http://nobelprize.org/nobel_prizes/physics/laureates/1986/) Within a year of the invention of the STM, Binnig and coworkers used the microscope to resolve the structure of the $\mathrm{Si}(111)$ (7x7) surface, one of the most intriguing unsolved problems in surface science at that time [4].

Despite the success of the STM, it became evident that a similar scanning microscope which could be used for nonconducting surfaces would be more useful. The STM requires that the sample material be electrically conductive, because the microscope uses the tunneling current which flows between a biased tip and the sample. It reflects the strong distance-dependent probability of electron transport through a gap between two conducting solids. With careful observation early in the STM experiments, Binnig became aware of significant forces detected with the tunneling current when the tip-sample distance was small enough for a 

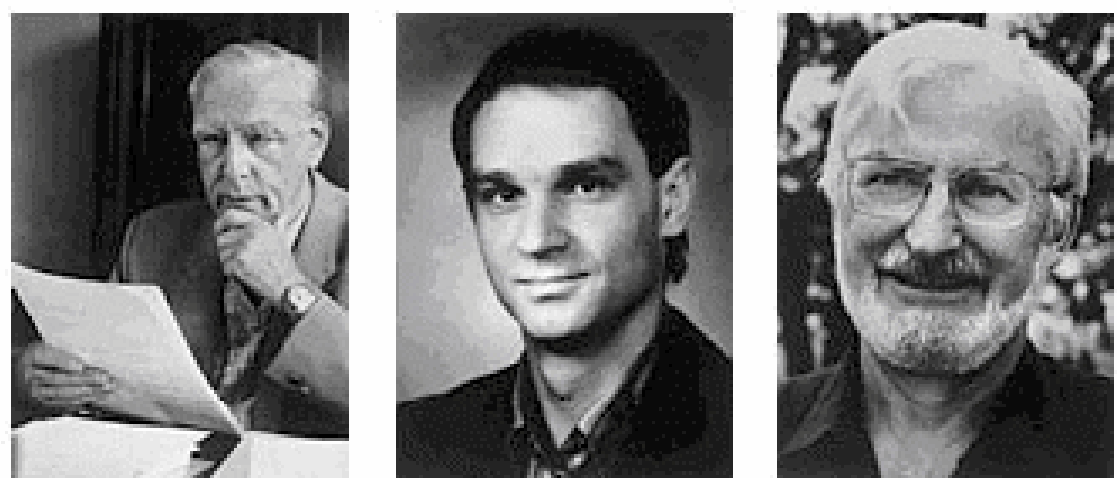

Fig. (2). Nobel Laureates Ernst Ruska, Gerd Binnig, and Heinrich Rohrer (left to right, picture from http://nobelprize.org/nobel_prizes/physics/laureates/1986/index.html). Ernst Ruska earned the prize for his fundamental work in electron optics, and for the design of the first electron microscope. Gerd Binnig and Heinrich Rohrer earned their prize for their design of the scanning tunneling microscope.

current to flow. In 1986 (while Gerd Binnig spent a sabbatical at Stanford with Calvin Quate and Christoph Gerber was at the IBM Research Laboratory in Almaden, California), they soon introduced a working prototype of the AFM $[2,5]$. The forces were based on the short-range van der Waals interaction when the tip-sample distance was small (see Fig. (3), [3]). Because no electron transport is involved, both insulators and biological samples can be investigated down to atomic resolution. Information on topography [6-11], roughness [9, 10], friction [8], adhesion $[8,11]$, elastic properties [12, 13], magnetic field [14, 15], resistivity $[16,17]$, etc. can be obtained by the AFM with nanometer resolution.

\section{PRINCIPLES OF ATOMIC FORCE MICROSCOPY}

Binnig described the AFM as being much like the stylus profilometer, in that both are used to scan the surface, sense the variations of the sample, and generate three-dimensional images [3]. The AFM consists of a probe with a very sharp

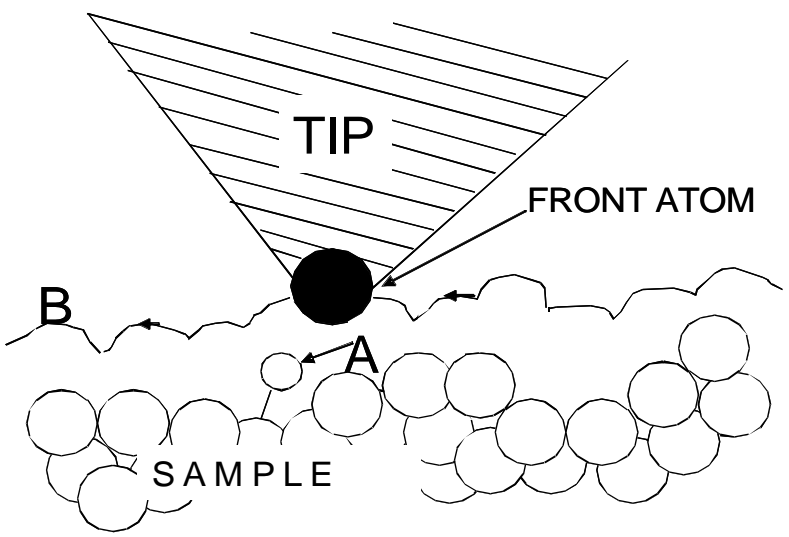

Fig. (3). Diagram of the short-range interaction force between the tip of the AFM (or STM) when in close contact with the sample surface [3].

tip that is attached to a cantilever. Today, probes are mass fabricated by the microlithography process, much like

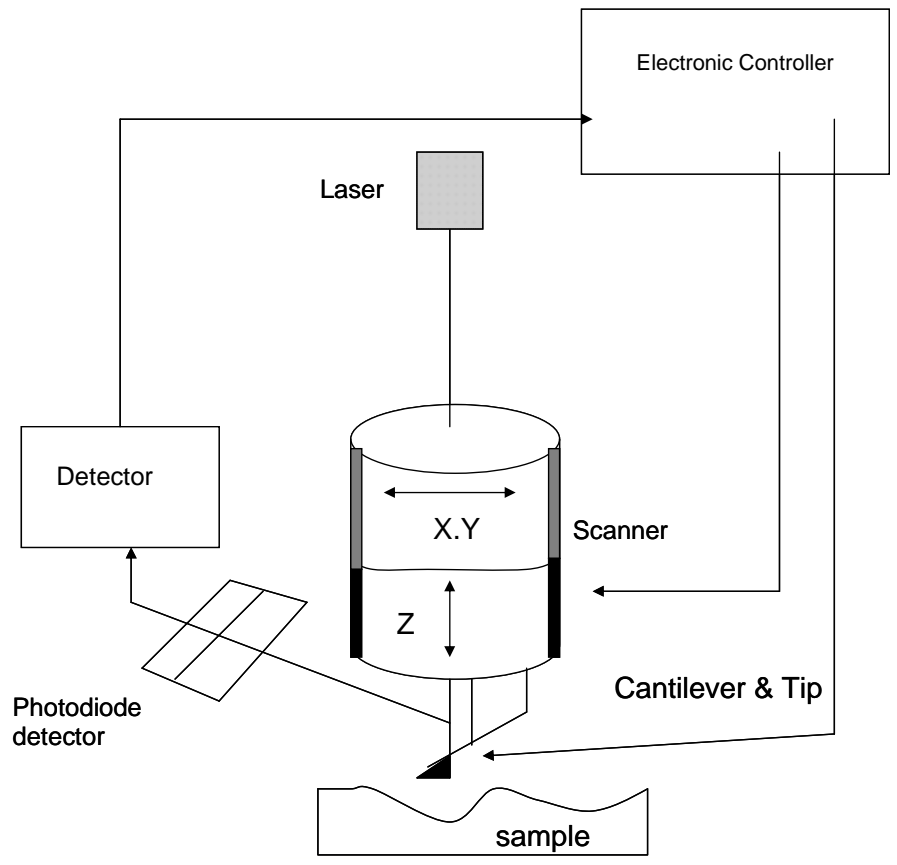

Fig. (4). Schematic diagram of the atomic force microscope. 
computer chips. Probes are typically made of silicon or silicon nitride with a tip radius of curvature on the order of 5-20 $\mathrm{nm}$. When the probe is scanned on the sample surface, the interaction between the tip and the atom on the surface of the sample causes the cantilever to bend as a result of van der Waals forces and other chemical bonds and forces. Forces on the probe can be either attractive or repulsive, depending on the nature of the interaction between the tip and the surface being investigated. The bending or deflection of the cantilever is in accordance to Hooke's law. The deflection of the cantilever is detected by a laser beam that is shined on the back of the cantilever and reflected onto a photodiode or a laser detector and processed by computer (Fig. 4). Aside from the signal from the photodiode, another important signal comes from the piezoelectric tube where the sample is placed. The translation of the piezoelectric tube height is controlled by a feedback loop, which can maintain either a constant force or a constant distance between the tip and sample. Signals from both the photodiode and the piezoelectric tube are analyzed by computer software and a 3-dimensional image of the surface is reconstructed.

\section{CHEMICAL MAPPING}

Surface interfacial properties can play an important role in governing many of the initial reactions that occur in biological systems, biomedical materials, drug delivery systems, materials science, chemical reactions, and many other areas. While there are several techniques that allow us to study the chemical spatial distribution of these surfaces, none are able characterize the surfaces in their natural environment on the nanometer length scale [18-23]. Chemical force microscopy (CFM) is a branch of the AFM where the probe is chemically modified or functionalized [24]. Characterization can be done in the natural environment of the system, as the AFM does not require a special vacuum to operate. The CFM is an applied concept of lateral force microscopy (LFM) and is also known as frictional force microscopy (FFM). It is called LFM or FFM because it measures the lateral twisting of the cantilever as a result of molecular friction (Fig. 5). Generally in the AFM, samples are scanned parallel to the direction of the cantilever setting which causes the up and down deflection of the cantilever (Fig. 6a). In LFM, the sample is scanned perpendicular to the direction of the cantilever setting in which the molecular friction causes a lateral twisting of the cantilever (Fig. 6b). A functionalized probe exhibits higher interaction (molecular frictional interaction) with specific domains on the specimen surface [25-31].

To detect a probe-specimen chemical interaction, three images of the same area are collected, namely the topography image, the lateral force (LF)-trace image, and the LF-retrace image. A topography image is often collected as a comparison to give information with regard to the $\mathrm{z}$-axis and also to determine the similarity of the scanned area and quality. LF-trace and LF-retrace images are collected in opposite scanned directions. A post-image processing, trace-minus-retrace (TMR), is performed on the LF-trace and LF-retrace images to eliminate the height differences of the scanned area. Fig. (7) shows a diagram of how doing the TMR can cancel out the height differences and put forth only chemical interaction information. However, TMR will not be able to cancel out large height differences. Fig. (8) shows the topography image of an acid-treated starch granule, and the TMR image after image subtraction that draws out the specific chemical domain's interaction between the tip and the specimen surface [29].
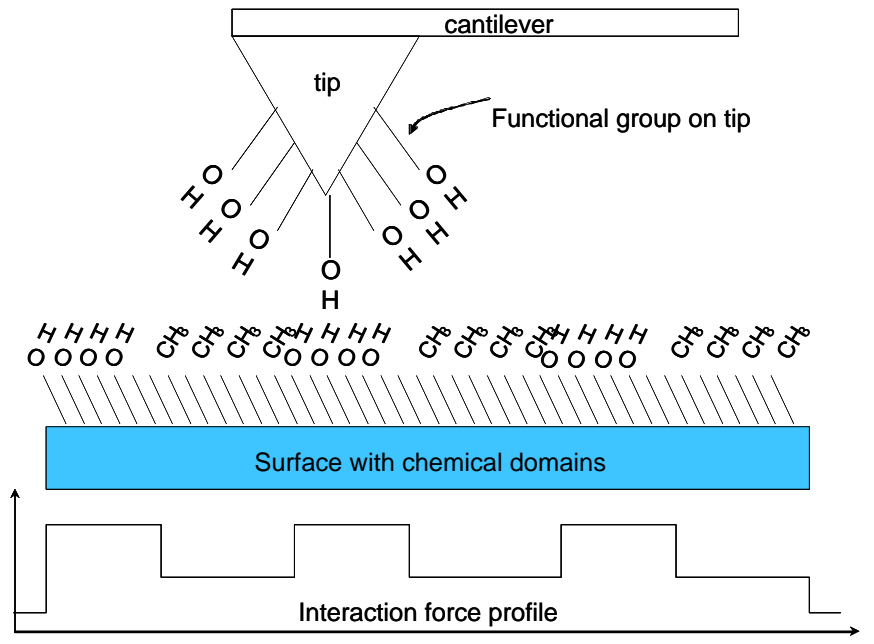

Fig. (5). Diagram of molecular friction interaction between a chemically modified probe and the surfaces of specific chemical domains.

\section{APPLICATIONS}

In 1994, Frisbie and co-workers first presented the working concept of the CFM in Science [32], where they focused on the adhesive and friction force measurement of organic monolayers of distinct functional groups. By using probe tips that have been functionalized with either hydrophobic $\left(\mathrm{CH}_{3}\right)$ or hydrophilic $(\mathrm{COOH})$ molecules, they showed that the adhesive interactions between simple hydrophobic-hydrophobic, hydrophobic-hydrophilic, and hydrophilic-hydrophilic molecules can be measured.

Since Frisbie et al.'s work, there have been continuous applications of the CFM in various biological systems and materials science to understand the chemical spatial distribution of different surfaces and their functions. Schönherr et al. had used the CFM to study the inhomogeneous forces that was related to the variations of local ' $\mathrm{pK}_{\mathrm{a}}$ ' values and different local hydrophobicity that result from the inhomogeneous distribution of the polar functional groups on the polymer surface [33].

Specificity of the receptor-ligand pair of cell membranes has also been used as CFM. Grandbois et al. had shown affinity contrast imaging of group $\mathrm{A}$ and $\mathrm{O}$ red blood cells with the CFM [34]. It would be impossible to mention all the work conducted via the CFM, but the work in this area is well acknowledged by the research community. Examples include work by Raghavan et al. [35], Nguyen et al. [36], Sugimoto et al. [37], Termnak et al. [27], Wuttisela et al. [29], and Hansma et al. [38] are few to mention.

\section{CONCLUDING REMARKS}

Chemical force microscopy allows investigators to measure molecular forces and the chemical properties of surfaces. A detailed understanding of chemical spatial distribution and the morphology of surface structures is of 


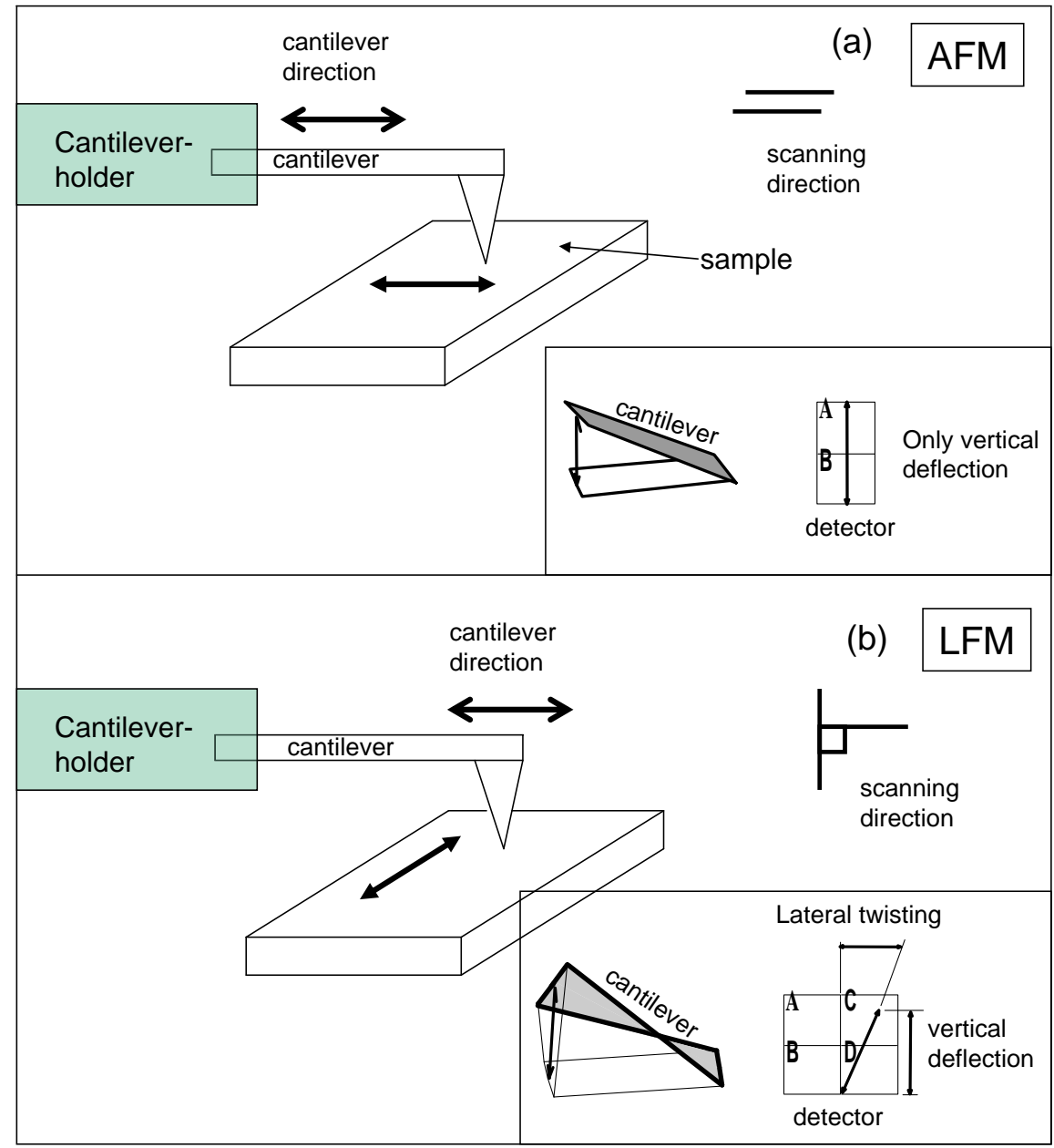

Fig. (6). Diagram to indicate the scanning direction of the cantilever. (a) Scanning parallel to the direction to which the cantilever is held by the cantilever holder results in only the vertical deflection of the cantilever in $A F M$; (b) Lateral twisting of the cantilever results from molecular friction and the scanning of the sample $90^{\circ}$ to the direction in which the cantilever is held by the cantilever holder in $L F M$.
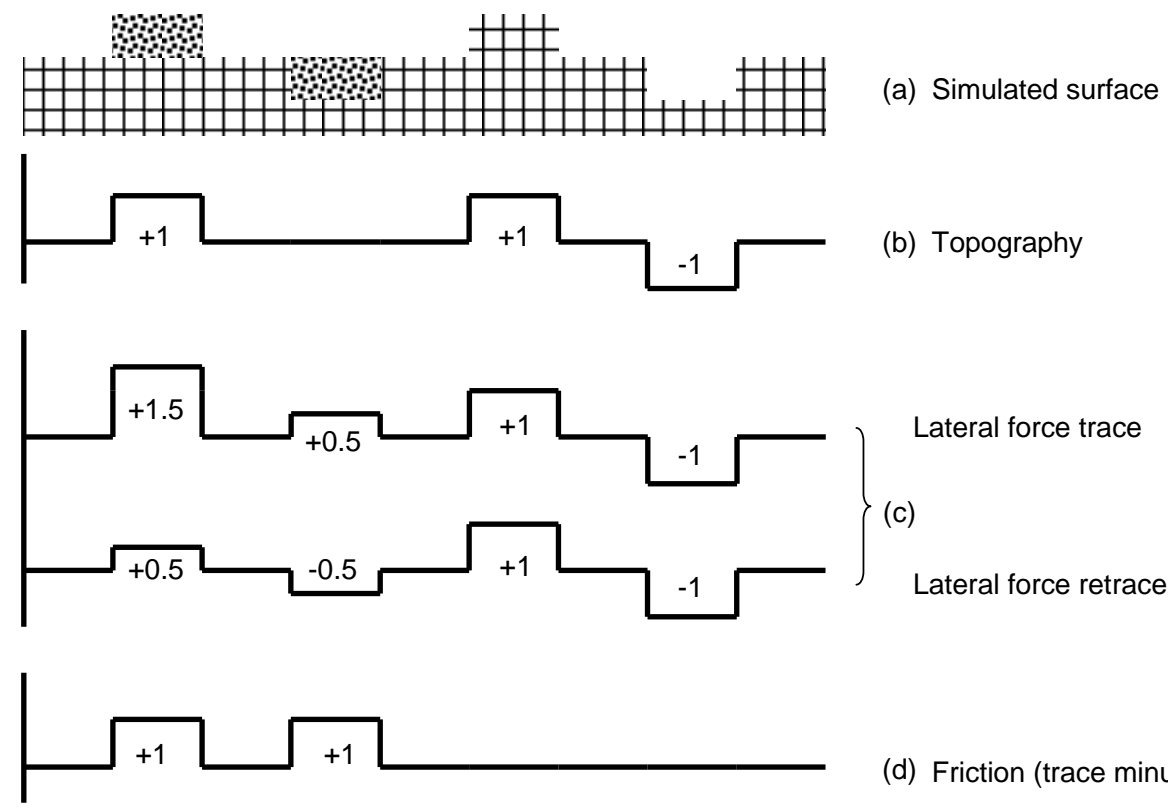

(d) Friction (trace minus retrace)

Fig. (7). Data processing concept of trace-minus-retrace (TMR). (a) Simulated surface with two types of materials having different chemical domains and areas with only height differences. (b) Topography profile of the simulated surface. (c) Lateral force (trace) and (retrace) profile, where both chemical domains and height information are coupled together, and lateral force (trace) and (retrace) information have opposite signs. (d) Result of trace minus retrace profile, leaving only the chemical domain information. 

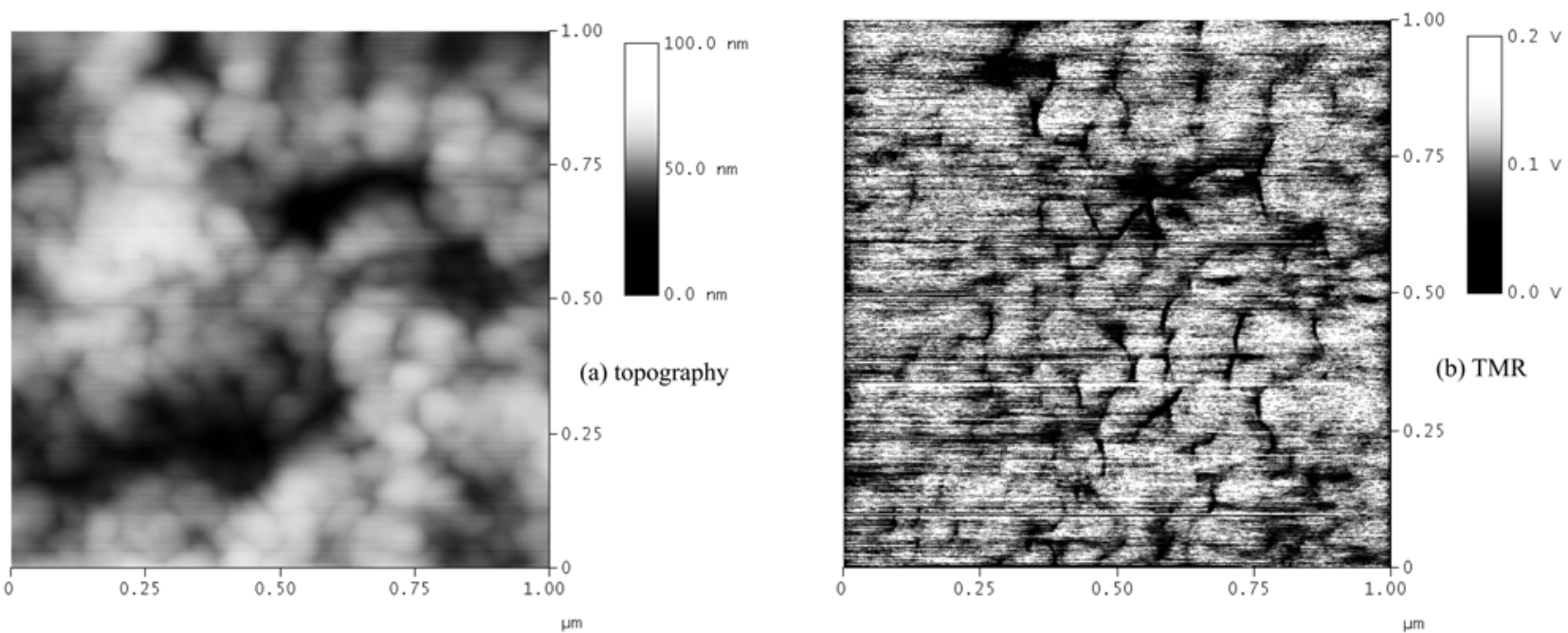

Fig. (8). (a) Topography image of a hydrolyzed starch granule using -OH probe. (b) TMR image that brings out a distinct chemical domain.

great importance, as it may govern the processes of many reactions that occur both in the bulk properties and on the nanoscale. It is most important to understand the nature of the surface being investigated to correctly interpret the interaction between the tip and sample.

\section{ACKNOWLEDGEMENTS}

We would like to thank David Blyler for editing this manuscript. This work has been supported by the Mahidol University Research Grant, The Thailand Research Fund (TRF), Center for Innovation in Chemistry (PERCH-CIC), The Thailand Center of Excellence in Physics (ThEP), Commission on Higher Education, and Ministry of Education.

\section{REFERENCES}

[1] Gerber C, Lang HP. How the doors to the nanoworld were opened. Nat Nanotechnol 2006; 1: 3-5.

[2] Riordon J. Physical Review Letters Top Ten. Number 4: atomic force microscopy. APS News 2003; 12(5): 3 .

[3] Binnig G, Quate CF, Gerber C. Atomic force microscope. Phys Rev Lett 1986; 56(9): 930-4.

[4] Binnig G, Rohrer H, Gerber C, Weibel E. 7x7 reconstruction on $\mathrm{Si}(111)$ resolved in real space. Phys Rev Lett 1983; 50: 120-3.

[5] Giessibl FJ. Advances in atomic force microscope. Rev Mod Phys 2003; 75: 949-83.

[6] Jang HN, No HJ, Lee JY, Rhee BK, Cho KH, Choi HD. The design, synthesis and nonlinear optical properties of a novel, Ytype polyurethane containing tricyanovinylthiophene of high thermal stability. Dyes Pigments 2009; 82(2): 209-15.

[7] Herting G, Lindström D, Wallinder IO, Leygraf C. Multi-analytical investigation of stainless steel grade AISI 420 in simulated food contact. J Food Eng 2009; 93(1): 23-31

[8] Nisbet DR, Rodda AE, Finkelstein DI, Horne MK, Forsythe JS, Shen W. Surface and bulk characterisation of electrospun membranes: Problems and improvements. Colloids Surf B Biointerfaces 2009; 71(1): 1-12.

[9] Zhang G, Meng H, Ji S. Hydrolysis differences of polyacrylonitrile support membrane and its influences on polyacrylonitrile-based membrane performance. Desalination 2009; 242(1-3): 313-24.

[10] Hoshi T, Matsuno R, Sawaguchi T, Konno T, Takai M, Ishihara K. Protein adsorption resistant surface on polymer composite based on 2D- and 3D-controlled grafting of phospholipid moieties. Appl Surf Sci 2008; 255(2): 379-83.

[11] Handojo A, Zhai Y, Frankel G, Pascall MA. Measurement of adhesion strengths between various milk products on glass surfaces using contact angle measurement and atomic force microscopy. $\mathbf{J}$ Food Process Eng 2009; 92(3): 305-11.
[12] Dimitriadis EK, Horkay F, Maresca J, Kachar B, Chadwick RS Determination of elastic moduli of thin layers of soft material using the atomic force microscope. Biophys J 2002; 82(5): 2798-810.

[13] Carpick RW, Ogletree DF, Salmeron M. Lateral stiffness: a new nanomechanical measurement for the determination of shear strengths with friction force microscopy. Appl Phys Lett 1997; 70(12): 1548-50.

[14] Gautreau O, Harnagea C, Gunawan L, et al. Piezoresponse force microscopy and magnetic force microscopy characterization of $\gamma$ $\mathrm{Fe}_{2} \mathrm{O}_{3}-\mathrm{BiFeO}_{3}$ nanocomposite/ $\mathrm{Bi}_{3.25} \mathrm{La}_{0.75} \mathrm{Ti}_{3} \mathrm{O}_{12}$ multiferroic bilayers. J Magn Magn Mater 2009; 321(11): 1799-802.

[15] Yoon J, Park SY, Jo Y, et al. Dense stripe domains in a nanocrystalline CoFeSiB thin film. Curr Appl Phys 2009; 9(3): $688-90$

[16] Reichenberg B, Tiedke S, Szot K, et al. Contact mode potentiometric measurements with an atomic force microscope on high resistive perovskite thin films. J Eur Ceram Soc 2005; 25(12) 2353-6.

[17] Stadermann M, Grube H, Boland JJ, et al. Simultaneous atomic force microscopy measurement of topography and contact resistance of metal films and carbon nanotubes. Rev Sci Instrum 2003; 74(8): 3653-5

[18] Schrader ME, Loeb GI, Eds. Modern Approaches to Wettability. Plenum: New York 1992.

[19] Hupfer B, Ringsdorf H. Surface and interfacial aspects of biomedical polymers. In: Andrade JD, Ed. Surface Chemistry and Physics. Plenum, New York 1985; vol. 1: p. 77.

[20] Feast WJ, MunroHS, Richards RW, Eds. Polymers and Interfaces II. Wiley \& Sons: New York; 1993

[21] Ulman A. An Introduction to Ultrathin Organic Films: From Langmuir-Blodgett to Self-Assembly. Academic Press: New York 1991.

[22] Briggs D, Seah MP, Eds. Practical Surface Analysis. Wiley: Chichester 1992

[23] Chan CM. Polymer Surface Modification and Characterization Hanser Publishers: Munich 1994.

[24] Ito T, Namba M, Bühlmann P, Umezawa Y. Modification of silicon nitride tips with trichlorosilane self-assembled monolayers (SAMs) for chemical force microscopy. Langmuir 1997; 13: 4323-32.

[25] Israelachvili JN. Intermolecular and Surface Forces, 2nd ed. Academic Press: New York 1992.

[26] Van der Vegte EW, Hadziioannou G. Scanning force microscopy with chemical specificity: an extensive study of chemically specific tip-surface interactions and the chemical imaging of surface functional groups. Langmuir 1997; 13: 4357-68.

[27] Termnak S, Sintasanai K, Nipithakul T, Amornsakchai T, Triampo D. Chemical morphology in grafting acrylamide to polyethylene. Chin J Polym Sci 2008; 26: 275-83.

[28] Nakagawa T, Ogawa K, Kurumizawa T. Atomic force microscope for chemical sensing. J Vac Sci Technol B 1994; 12: 2215-8. 
[29] Wuttisela K, Triampo W, Triampo D. Chemical force mapping of phosphate and carbon on acid-modified tapioca starch surface. Int J Biol Macromol 2009; 44: 86-91.

[30] Noy A, Vezenov DV, Lieber CM. Chemical force microscopy. Annu Rev Mater Sci 1997; 27: 381-421.

[31] Van der Vegte EW, Hadziioannou G. Acid-base properties and the chemical imaging of surface-bound functional groups studied with scanning force microscopy. J Phys Chem B 1997; 101(46): 9563-9.

[32] Frisbie CD, Rozsnyai LF, Noy A, Wrighton MS, Lieber CM. Functional group imaging by chemical force microscopy. Science 1994; 265(5181): 2071-4

[33] Schönherr H, van Os MT, Hruska Z, et al. Towards mapping of functional group distributions in functional polymers by AFM force titration measurements. Chem Commun 2000; 1303-4
[34] Grandbois M, Dettmann W, Benoit M, Gaub HE. Affinity imaging of red blood cells using an atomic force microscope. J Histochem Cytochem 2000; 48: 719-24

[35] Raghavan D, Gu X, VanLandingham M, Nguyen T. Mapping chemically heterogeneous polymer system using chemical modification and atomic force microscopy. Polymer 2000; 41(2): $1423-4$

[36] Nguyen $\mathrm{T}, \mathrm{Gu} \mathrm{X}$, Fasolka $\mathrm{M}$, et al. Mapping chemical heterogeneity of polymeric materials with chemical force microscopy. Polym Mater Sci Eng 2004; 90: 141-3.

[37] Sugimoto Y, Pou P, Abe M, et al. Chemical identification of individual surface atoms by atomic force microscopy. Nature 2007; 446: 64-7.

[38] Hansma HG, Hoh JH. Biomolecular imaging with the atomic force microscope. Annu Rev Biophys Biomol Struct 1994; 23: 115-39.

(C) Triampo and Triampo; Licensee Bentham Open

This is an open access article licensed under the terms of the Creative Commons Attribution Non-Commercial License (http://creativecommons.org/licenses/by-nc/ 3.0/) which permits unrestricted, non-commercial use, distribution and reproduction in any medium, provided the work is properly cited. 